\title{
The Effect of Pull Power of Karaoke Television-set Service on the Inner Need of Consumer
}

\author{
Jiun-Hung Lin
}

Department of Marketing and Logistics Management, China University of Technology, No. 530, Sec. 3, Jhong-Shan Road, Hukou Township, Hsin Chu County, 3.

Email: linjinghung.tem89g@nctu.edu.tw, jiun.hunglin@msa.hinet.net

Received June, 2013

\begin{abstract}
KTV is an important recreation activity in Taiwan. Since the recreation activities are more diversified because of the progress of information technology and the leisure policy of government lead to many free recreation places and activities existed, KTV service as a kind of recreation activities but not free and face a keener competition. This study tries to explore how to strengthen the thrust for consumer to choose KTV as their recreation activity through understanding the motivations for KTV consumption with empirical data and provides suggestions to help improve the KTV service.
\end{abstract}

Keywords: Motivation; Karaoke TV (KTV)

\section{Introduction}

Karaoke television-set (KTV) is a form of interactive musical entertainment service provides independent private room and interactive musical facilities for consumer to sing song with friends or family [1].

Since 1990, KTV is an important recreation activity in Taiwan [2]. However, the recreation activities are more and more diversified because of the arise of internet and handy smart phone and local government constructs many green and free public parks and places with holding many festival and activities to attract people to participate and consume. KTV service as a kind of recreation activities but is not free and face a keener competition.

How to strengthen the thrust for consumer to choose KTV for their recreation through understanding the inner motivations for KTV consumption and strengthen those inner motivations by improving the KTV service factors become important issues to be studied.

\section{Theoretical Backgrounds}

\subsection{Karaok TV (KTV)}

Sha [1] indicate KTV is originated from Karaoke came from Japan. Karaoke which means singing in a public stage with the accompaniment of an orchestra without anybody is introduced to Taiwan in the early 1980 . However, it need consumer with courage and dare to sing in the public but not the case for everyone. Hence, the popularity of Karaoke is limited [3]. In the early 1990, business in Taiwan developed a new type of recreation service to combine Karaoke with an independent and private room and is called as Karaoke television-set (KTV) [1]. KTV is a singing place provides an independent and private room for consumer to sing with a vocal accompaniment video tape broadcasted on a larger television and stereo facility. Beverage and meal is also provided for consumer [4].

\subsection{Motivation of Leisure Activity}

Psychologists interpret motivation with different viewpoints and indicate motivation is highly related to what people talk and behave. Motivation is the drive of an individual behavior [5]. "Push factor" and "pull factor" are two factors that can induce individual behavior reaction [5-7]. "Push factor" means an inner drive that would guide individual behavior. While a motivation of individual is satisfied, this motivation would be eliminated. Inner needs or socio-psychological motives such as social with others or escape routine are commonly push based motivations for recreations activities [5, 6]. "Pull factor" is induced by the service itself. The characteristics of the service itself that would attract consumer such as having special atmosphere, exciting facilities, or convenient location are commonly pull based motives for recreations activities [5,6].

Previous researches proposed the motives drive consumer to KTV includes organizing a social party for family or friends, having flow across each other with family or friends, seeking for entertainment and exciting, 
escaping daily routine and forgetting trouble, practicing singing, relaxing stress, venting feeling or emotion, and contenting the feeling to be a start $[3,8,9]$.

KTV is a "heterologous space for experiencing imagination" and "the great decoration of the independent and private room [10].” Zhang [10] indicates that the living room like design of the KTV room provides a place for consumer to have and share fun with friends. The KTV room is an isolated, safety, and private place and can make a small group abandon themselves to sing songs without any disturbance. The songs called for singing, the stars that perform the songs, and the vocal accompaniment video tape in the KTV room all can be the topic to talk and induce pleasant feeling of interpersonal relationship. Accordingly, the stateroom of KTV leads to stronger and closer interpersonal relationship among people in the room.

\section{Research Model and Methodology}

Based on the discussions in previous sections, this research develop hypothesis to be empirical tested as below.

H1: Pull power of KTV service is positively related to the push power of internal need.

Pull power of KTV service and push power of internal need are measured through measurement scales developed by this study. Factor analysis is used to extract the factors of Pull power of KTV service and push power of internal demand.

Likert seven point scale from very disagree to very agree is used to measure all items. All the questionnaires were answered by the KTV consumer in Taiwan. Regression is used to validate the assumptions developed.

\section{Result}

Four hundred questionnaires were delivered and 257 valid questionnaires received, representing an effective response rate of $64 \%$.

Factor analysis is used to extract the factors of pull power of KTV service and push power of internal need. Results of factor analysis indicated that KMO values of both pull power of KTV service and push power of internal need are above 0.85 and Bartlett's Test of Sphericity for each construct is also significant at $\mathrm{p}$-value $<0.01$. Four factors are extracted for pull power of KTV service and $69.9 \%$ of variance is extracted. Those factors are "V11: Nice general services setting and quality", "V12: Located in urban flourishing business district," "V13: Wonderful singing related facilities," and "V14: Located in recreation and entertainment district.”

Three factors are extracted for push power of internal need and $60.8 \%$ of variance is extracted. Those factors are "V21: Improve interpersonal relationship through self-expression by singing songs," "V22: Entertainment," and "V23: Organizing a social party."

The regression analysis result indicates the standardized path coefficients and $R^{2}$ for each regression function in this study are all presented in Figure 1. The $R^{2}$ values for "improve interpersonal relationship through self-expression by singing," "Entertainment," and "Organizing a social party” are $0.21,0.12$, and 0.16 , respectively.

"Nice general services setting and quality" is not significantly positively related to "improve interpersonal relationship through self-expression by singing”, "entertainment”, and “organizing a social party”.

"Located in urban flourishing business district" is significantly positively related to both "improve interpersonal relationship through self-expression by singing" and "organizing a social party". However, "located in urban flourishing business district" is not significantly positively related to "entertainment".

"Wonderful singing related facilities" is significantly positively related to "improve interpersonal relationship through self-expression by singing”, “entertainment”, and "organizing a social party".

"Located in recreation and entertainment district" is significantly positively related to both "improve interpersonal relationship through self-expression by singing” and "entertainment”. However, Located in recreation and entertainment district is not significantly positively related to "organizing a social party”.
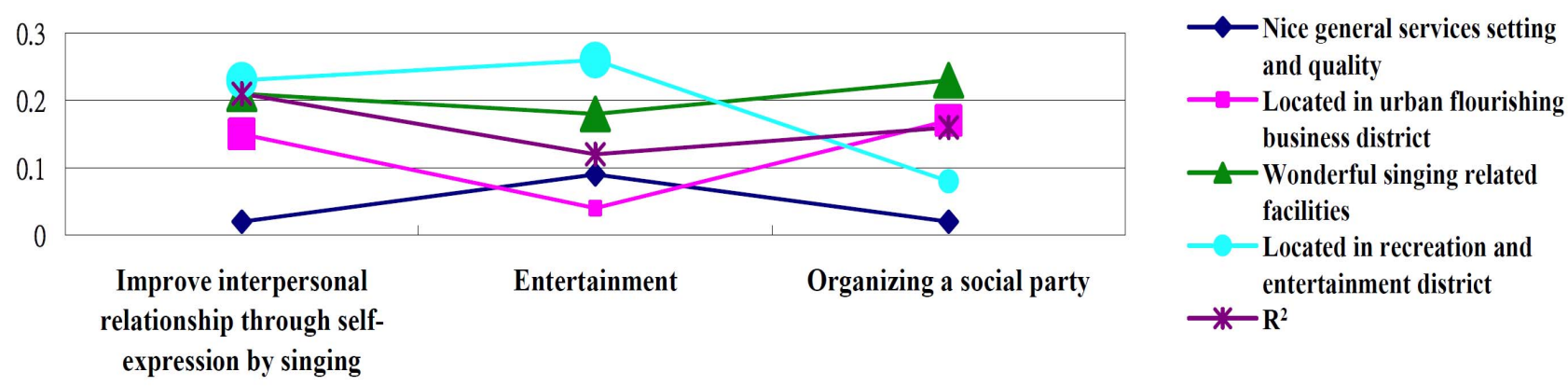

*Big bold point denotes a significant path $(\mathrm{p}<0.01)$.

Figure 1. Results of theoretical model. 


\section{Conclusions}

Based on the research result of this research, the motives for consumer to KTV can classified in to push based motives which are the inner drives that would guide individual behavior and pull based motives induced by the service itself that would strengthen the push based motives. The three main push power of internal need for consumer to KTV are 'improve interpersonal relationship through self-expression by singing songs,' 'entertainment,' and 'organizing a social party.' The four main pull power induced by the characteristics of the KTV service itself are 'nice general services setting and quality,' 'located in urban flourishing business district,' 'wonderful singing related facilities,' and 'located in recreation and entertainment district.'

In order to attract consumer to consume KTV service, KTV stores should provide wonderful singing related facilities in each KTV room and are recommended to set their KTV stores located in both 'urban flourishing business district' and 'famous recreation and entertainment district'. The general hardware and service outside the KTV room such as the lobby setting is suggested to be set in an acceptable level as the average industry standard.

\section{REFERENCES}

[1] G. G. Sha, "The Politic Economic of Recreation- the First Analysis to the KTV in Taiwan," Journal of Outdoor Recreation Study, Vol. 5, No. 2, 1992, pp. 145-163.

[2] Y. Z. Chiang, “One Million Lonely Heart Wait for Hap- piness in the Three Metro City,” Global Views Magazine, Vol. 238, 2006, pp. 166-174.

[3] F. S. Su, "The Study of Motivations, Obstructions, and Health Effects of Teenage Students to Sing at KTV Stores," Unpublished Master Thesis of Department of Leisure and Recreation, Asia University, Taichung Taiwan, 2006.

[4] DCAMEA (Dept of commercial affairs of Ministry of Economic Affairs), "The Change and Future Trend of Audio-visual Entertainment Industry," Annual Report of Service Business in Taiwan, 2000, pp. 21-46.

[5] D. Fodness, "Measuring Tourist Motivation," Annals of Tourism Research, Vol. 21, No. 4, 1994, pp. 555-581. doi:10.1016/0160-7383(94)90120-1

[6] J. Gnoth, "Tourism Motivation and Expectation Formation," Annals of Tourism Research, Vol. 24, No. 2, 1997, pp. 283-304. doi:10.1016/S0160-7383(97)80002-3

[7] Z. S. Chang, “Chang’s Psychology Dictionary,” Taipei: Tunghua. Publish Ltd., 1990.

[8] T. L. Cheng, "The Study of "KTV" Consumer's Motives and Behaviors," Unpublished Master Thesis of Department of News, Chinese Cultural University, Taipei, Taiwan, 1993.

[9] Y. F. Chen, “A Study of Key Determinants of Hedonic Experience in KTV Industry,” Unpublished Master Thesis of Department of Marketing and Logistics, National Kaohsiung First University of Technology, Kaohsiung, Taiwan, 2006.

[10] S. M. Zhang, "Leisure, Pleasure, and Power-a Sociological Analysis of KTV in Taiwan,” Unpublished Master Thesis of Graduate Institute of Building and Planning, National Taiwan University, Taipei, Taiwan, 1993. 